\title{
Ring Chromosome 12
}

National Cancer Institute

\section{Source}

National Cancer Institute. Ring Chromosome 12. NCI Thesaurus. Code C158951.

An aberration of chromosome 12 where the arms have fused to form a ring. 